\title{
The HRM Tango Impact of Availability and Use of Flexibility HR Practices on Organizational Performance
}

\author{
Dr. Ayman Mobarez \\ Canadian International College (CIC) \\ Arab Republic of Egypt
}

\begin{abstract}
This research investigated the effects of flexibility HRM on employee outcomes over time, as well as the role of age in these relations.

Based on work adjustment theory, it was predicted that availability and use of flexibility HRM would be positively related to employee engagement, as well as higher job performance. Moreover, the researcher postulated different hypotheses regarding the role of employee age. While generation theory predicts that younger generations would react more strongly to flexibility HRM in relation to engagement, SOC-theory of aging predicts that older workers respond more strongly in relation to job performance.

Moreover, the researcher found partial support for the moderating role of age in the relations of flexibility HRM with the outcomes: Flexibility HRM was important for younger workers to enhance engagement, while for older workers it enhanced their job performance.

The research shows that the effectiveness of flexibility HRM depends upon employee age and the type of outcome involved, and consequently theory on flexibility at work should take the age of employees into account.

Keywords: Flexibility HRM, Engagement, Older Workers, Employee Age; Generation Differences, organization performance, employee outcome.
\end{abstract}

\section{Introduction}

Flexibility is an important goal of Human Resource Management (HRM) (Boxall \& Purcell, 2011; Guest, 1987).

Flexibility' is generally seen as the ability of organizations to cope with the dynamics and the uncertainty of their environments by rapidly changing their organizational routines or resource bases. Flexibility is not a passive reaction to changes in the environment, but refers to the ability of organizations to proactively engage with their environments and to make changes in order to be successful (Gerwin, 1993; Sanchez, 1995).

Since organizational environments have become more complex and dynamic, organizations increasingly use HRM practices that enhance their flexibility, such as contingent work, part timers, temporary work or contract work (Kalleberg, 2000).

Much research has been carried out on the question of how flexibility can be achieved within HRM (e.g., Mayne et al., 1996; Wright \& Snell, 1998; Lai et al., 2008).

\footnotetext{
* This article was submitted in March 2018, and accepted for publishing in July 2018.
} 
In general, this research stream assumes that flexible HRM has economic merits and is Therefore an appropriate and legitimate goal of HRM.

However, as we shall see, the debate over flexible HRM has been accompanied by criticism of the negative side effects of flexible HRM practices.

Researchers with sociological backgrounds have extensively discussed job insecurity, which has increased in parallel with the increase in flexible working practices (Beck, 2000; Cooper, 2008; Doogan, 2001; Hesseling \& van Vuuren, 1999; Lambert, 2008).

Researchers who are more interested in psychological effects have focused on the increase in job stress, burn-out rates, mental ill-health (e.g., employment-related depression) and physical health problems (e.g., chronic back pain) (Docherty et al., 2002; Strazdins et al., 2004). Flexibility in HRM can therefore be an ambiguous concept: on the one hand, it is an essential element of strategic HRM and a prerequisite for competitive advantages, while on the other hand, flexible HRM has been criticized for its negative effects on Workers and society.

The searcher argue that these two perspectives follow different research Streams and different perspectives, broadly presenting a managerial and a non-managerial Perspective. Both research streams have been discussed separately and have remained mutually incomprehensible within certain limits (see, for example, the discussion about 'flexicurity', see Wilthagen \& Tros, 2004). Furthermore, the differentiation between the 'hard' and 'soft' approaches of flexible HRM (Truss et al., 1997; Roan et al., 2001) has hindered integrated discussions within the managerial perspective.

Therefore, the discussion surrounding flexible HRM lacks analytical frameworks for an integrated discussion of the positive and negative effects of flexible HRM.

The Research contributes to previous research on the effects of flexibility HRM by being the first study to specifically focus on the effectiveness of availability and use of flexibility HRM on work outcomes for younger and older workers (De Menezes \& Kelliher, 2011).

Some previous studies have failed to find significant effects of flexibility HRM on outcomes such as commitment (Herrbach et al., 2009) and organizational support (Armstrong-Stassen \& Ursel, 2009). This Research builds upon these earlier studies by investigating effects of both availability and use of flexibility HRM, and This Research contributes by studying active work states, such as engagement and performance, rather than passive work states, such as commitment or organizational support.

This Research also contributes by showing both how and when flexibility relates to outcomes, and thus shows both mediating and moderating effects.

Moreover, the Research contributes by being the first paper that both theoretically and empirically integrates theory on flexibility HRM with generation and aging theory in one study by showing that age moderates the effects of flexibility HRM on outcomes in different ways. Finally, the Research contributes by not only longitudinally investigating relationships of flexibility HRM with outcomes, but also through presenting evidence for the existence of relationships in various organizations. The current multi-sample study consists of two studies, one of which was a longitudinal study among Egyptian employees, while the second study tested the hypotheses in a sample of employees in Four Egyptian and Multinational organizations In Industrial Zone 6 Oct, City and Heliopolis in Egypt.

Flexibility is becoming more important among the younger generations as well as aging workers across the Organizations (Lewis, Rapoport \& Gambles, 2003; Lyons \& Kuron, 2014). To control for cultural differences across these Organizations in the relationships observed, we included collectivism as additional moderator in 
the analyses. Masuda et al. (2012) argued and found that in more individualistic Organizations, which tend to be more focused on individual employment arrangements (Peretz \& Fried, 2012), flexible work arrangements were more likely to be used and more strongly related to work outcomes than in collectivistic Organizations. Hence, we explored whether the relations would be less prominent among collectivistic Organizations.

\section{Research Problem}

The main questions of this research are:

Does the Flexibility HRM can be used by organizations to enhance younger workers' engagement, while it can be used for older workers to enhance their job performance?

- Is it important for organizations to not only offer flexibility to their employees, but also to make sure that employees take advantage of these HR practices?

- Does Flexibility HRM is important across the organizations, because it enables people across the organizations to balance demands from work as well as from private life?

During This study the searcher hopes to find out the answers on these research questions.

\section{Literature Review}

\section{Strategic Flexibility}

Strategic flexibility has been defined as «a firm's abilities to respond to various demands From dynamic competitive environments,》(Sanchez, 1995: 138).

Flexibility provides Organizations with the ability to modify current practices in response to no transient changes in the environment.

Weick (1979) argues that flexibility requires detecting changes in the environment and retaining a sufficient pool of novel actions so that these changes can be accommodated.

In contrast, Teece, Pisano, and Shuen described the need for firms in dynamic environments to reconfigure the firm's asset structure, and to accomplish the necessary internal and external transformations. (1997: 520). They refer to high flexibility firms as those with a capability to scan the environment, evaluate markets and competitors, and to quickly Accomplish reconfiguration and transformation ahead of competition. (1997: 520)

Thus, numerous authors have proposed that in dynamic or uncertain environments, flexibility Promotes organizational effectiveness and survival (Chakravarthy, 1982; Miles \& Snow, 1978; Weick, 1979).

\section{The Hard and Soft Models of Flexible HRM}

Not long after its inception, research on HRM was acknowledged as being divided into A 'hard' and a 'soft' model. The hard model is characterized by its calculative, quantitative Approach to the strategic contributions of HRM and addresses challenges such as strategic fit (between HRM strategy and business strategy) or internal fit (between HRM practices themselves) (e.g., Tichy et al., 1982).

This approach is also intertwined with direct and tight managerial control over human resources, which «is widely acknowledged to place little emphasis on workers' concerns» (Guest, 1999, p. 5).

According to Truss et al. (1997), the tightness of the hard model of HRM can be traced back to its roots in scientific management and McGregor's 'Theory $X^{\prime}$. In contrast, the soft model is a broader approach to HRM. In terms of the consequences of HRM practices, the soft model incorporates not only organizational 
effectiveness, but also individual and societal effects (e.g., Beer, 1985). While the hard model focuses on strategic perspectives, the soft model is more engaged with the human aspect of HRM. The soft model rests upon McGregor's 'Theory $\mathrm{Y}^{\prime}$ and emphasizes the motivation, commitment, involvement and participation of employees. The main assumption of this approach is that employees will work most efficiently when They are motivated and committed to the organization (Truss et al., 1997).

The hard and the soft models of HRM offer different approaches to the phenomenon of flexible HRM. Researcher have argued that the different forms of hard and soft HRM are related to different forms of flexible HRM: Systems such as flexible staffing arrangements (use of temporary staff agencies or part-time contracts) aimed at enhancing numerical flexibility have more in common with the hard model of HRM. (Guest, 1987, p. 514; Kalleberg, 2001; Knox \& Walsh, 2005; Truss et al., 1997, p. 54).

By contrast, the soft model of HRM is primarily associated with behavioral and skill based Flexibility. The negative effects of flexible HRM on workers or society are usually related to the 'hard' versions of flexible HRM (e.g., Lambert, 2008).

The critics of such practices are based on following arguments: flexible practices which reduce job security or entail lower wages for contractual or temporary workers are obviously applied in order to achieve the business objectives of the firm and to fulfill performance criteria. Therefore, firms can easily be criticized for failing to strike a balance between the interests of employers and employees and for pursuing unethical practices if they use flexible HRM strategies (Kochan, 2008; Winstanley et al., 1996a, p. 6, 1996b, p. 189).

Positive aspects of flexible HRM, however, are related to the soft model of HRM. Highly committed employees are more motivated to learn in order to enhance their behavioral repertoires and their 'technical' skill bases.

Additionally, the soft model of HRM includes conceptual ideas such as training, employee involvement, and participation programs and job enlargement, which can all be seen as part of employee development. In accordance with this, Guest noted that «employee flexibility is only feasible if employees at all levels display high organizational [sic] commitment, high trust and high levels of intrinsic motivation» (Guest, 1987, p. 514). It is possible to denote this system as a 'soft' component of flexible HRM. These systems of flexible HRM generally have positive connotations.

\section{The Debate Surrounding Flexible HRM and its Limitations}

From the very beginning of the flexibility debate, the question has arisen whether flexibility is 'good' or 'bad' (Salvati, 1989, p. 43; see also Prieto, 1993, p. 615).

Indeed, the biased statement made by Pollert (1991b, p. 9) that the flexibility debate generally follows the basic assumption that «rigidity is dysfunctional; flexibility, functional» falls short. Instead, there are both positive and negative research findings concerning flexible HRM. However, why is it not possible to answer the question of whether flexibility is positive or negative2 Certainly, the complexity of the phenomenon results in one (valid) answer.

However, this answer does not help us in coping with flexibility as a research topic. For scientific purposes, it is necessary to identify the principles and logic which lie behind the difficulty of integrating and understanding the negative and managerial perspectives.

Second, the managerial perspective of flexible HRM is, within itself, based upon a soft and a hard model of HRM (Truss et al., 1997). In our quest to elaborate upon a research framework which offers the opportunity to integrate different Research findings and to foster more reflexive research on flexible HRM, the searcher will depict these two underlying principles in the following part of this research. 


\section{Fit and Flexibility in Strategic Human Resource Management}

The elevation of domestic and global competition has forced firms to examine all resources at their disposal in order to gain competitive advantage (Barney, 1991; Hamel and Prahalad, 1994).

Not surprisingly, attention to the competitive potential of the employees or human resources has increased substantially (Huselid, 1995; Lado \& Wilson, 1984; Miles \& Snow, 1984; Schuler \& MacMillan, 1984; Wright, McMahan, \& McWilliams, 1994).

The field of Strategic Human Resource Management (Strategic HRM) focuses specifically on the role of human resources in improving firm performance or competitive advantage. Wright \& McMahan (1992) defined Strategic HRM as «the pattern of planned human resource deployments and activities intended to enable the firm to achieve its goals,» (p. 298).

This definition emphasizes congruence or fit between HR and strategy. In fact, they argued that HR fit consists of two types. First, vertical fit involves the alignment of human resource management (HRM) practices and the strategic management process of the firm (Schuler \& Jackson, 1987).

Second, horizontal fit implies congruence among the various HRM practices (Baird \& Meshoulam, 1988). Achievement of horizontal fit is viewed as instrumental for efficiently allocating human resources. Vertical fit, in turn, is viewed as directing those resources toward the primary initiatives of the organization.

Despite the pervasive discussions of fit, emphasis has increasingly been placed on the Concept of flexibility in Strategic HRM (Kerr \& Jackofsky, 1989; Lengnick-Hall \& Lengnick-Hall, 1988; Milliman, Von Glinow, \& Nathan, 1991).

Researchers in the area of Strategic HRM Advocate that in the current complex and dynamic environment, organizations require flexibility to adapt to the diverse and changing requirements (Snow \& Snell, 1993).

From this perspective, Strategic HRM is primarily concerned with developing the organizational capability to adapt to changing environmental contingencies (Snell, Youndt \& Wright, 1996).

At first glance, it might appear that the desirability of strategic fit and the need for Organizational flexibility is in conflict. Indeed, the relationship between fit and flexibility in the context of Strategic HRM is not well understood, and little agreement exists regarding the Definitions and value of each.

The purpose of this paper is to present a framework which provides a theoretical foundation for understanding the strategic role of human resources in organizations through both fitting important aspects of the HR system to the strategic needs of the firm and building these components so as to enable flexible response to a variety of strategic requirements.

In order to do so, the research will first examine the concepts of fit and flexibility and their Relationship to one another. The searcher will then explore the past conceptualizations of fit in Strategic HRM relative to HRM practices, employee skills, and employee behaviors. Based on this work, and propose a model of Strategic HRM which includes both fit and flexibility components. The paper will then examine the concept of flexibility in Strategic HRM, and explore the factors that can promote and/or impede achieving flexibility.

Finally, the implications for Strategic HRM practice and research will be discussed. Organizations use flexibility HRM to maintain employee motivation and performance (Herrbach, Mignonac, Vandenberghe, \& Negrini, 2009).

However, because flexibility HRM has primarily been designed for middle-aged workers with children (Allen et al., 2013), it is necessary to investigate the effects of flexibility for younger generations, as well as older workers (Bal, De Jong, Jansen, \& Bakker, 2012; Kooij et al., 2013). To investigate this, it is essential to differentiate between the effects age can have on the outcomes of flexibility HRM. 
Both literatures on younger workers (e.g., Hess \& Jepsen, 2009; Lub, Bijvank, Bal, Blomme, \& Schalk, 2012) and older workers (Bal et al., 2012; Pitt-Catsouphes \& Matz-Costa, 2008) have stressed the importance of flexibility in how employees conduct their work, and how work is combined with other aspects in life. Generation theory (Twenge et al., 2010, 2012) predicts that younger workers attach more value to flexibility at work and hence become more emotionally affected when they have flexibility. In addition, Lifespan theory of Selection, Optimization, and Compensation (SOC; Baltes, 1997; Baltes \& Baltes, 1990) explains that older workers experience age-related losses in capabilities and decline of health. To counteract the negative consequences of age-related losses, older workers may use flexibility to maintain their performance. Lyons and Kuron (2014), in their recent review, concluded that saliency of flexibility and work-life balance has increased over generations, but at the same time, life-cycle effects also existed. They found that work-life balance has become more important among younger generations, but at the same time studies have shown curvilinear effects, indicating that work-life balance also becomes more important among older workers (Lyons \& Kuron, 2014). The current study specifically aims to unravel these different effects of employee age, by simultaneously hypothesizing and testing generation effects and aging effects.

In the current study, we accordingly investigate the role of age in the effects of flexibility HRM on employee engagement and job performance, while taking into account both the availability and the use of flexibility HRM (Allen et al., 2013). Moreover, we investigate the mediating role of employee engagement in the relations between flexibility HRM and job performance. Employee engagement is defined as a positive work-related state of mind characterized by vigor and dedication to the job (Schaufeli \& Bakker, 2004). Engagement is of importance in relation to flexibility HRM, because flexibility HRM is designed to retain a balance between work obligations and private obligations, through which employees can stay and become engaged in their work (Pitt-Catsouphes \& Matz-Costa, 2008). Moreover, we investigate the effectiveness of flexibility HRM for younger and for older workers.

The study contributes to previous research on the effects of flexibility HRM by being the first study to specifically focus on the effectiveness of availability and use of flexibility HRM on work outcomes for younger and older workers (De Menezes \& Kelliher, 2011). Some previous studies have failed to find significant effects of flexibility HRM on outcomes such as commitment (Herrbach et al., 2009) and organizational support (Armstrong-Stassen \& Ursel, 2009). Our paper builds upon these earlier studies by investigating effects of both availability and use of flexibility HRM, and our paper contributes by studying active work states, such as engagement and performance, rather than passive work states, such as commitment or organizational support. Our paper also contributes by showing both how and when flexibility relates to outcomes, and thus shows both mediating and moderating effects.

Moreover, the study contributes by being the first paper that both theoretically and empirically integrates theory on flexibility HRM with generation and aging theory in one study by showing that age moderates the effects of flexibility HRM on outcomes in different ways. Finally, the study contributes by not only longitudinally investigating relationships of flexibility HRM with outcomes, but also through presenting evidence for the existence of relationships in various countries across the world The current multi-sample study consists of two studies, one of which was a longitudinal study among US employees, while the second study tested the hypotheses in a sample of employees in eleven countries across the world. Flexibility is becoming more important among the younger generations as well as aging workers across the world (Lewis, Rapoport \& Gambles, 2003; Lyons \& Kuron, 2014). To control for cultural differences across these countries in the relationships observed, we included collectivism as additional moderator in the analyses. Masuda et al. (2012) argued and found that in more individualistic countries, which tend to be more focused on individual employment arrangements (Peretz \& Fried, 2012), flexible work arrangements were more likely to be used and more strongly related to work outcomes than in collectivistic countries. Hence, we explored whether the relations would be less prominent among collectivistic countries. Figure 1 shows the research model that will guide the current study. 


\section{Fit vs. Flexibility or Fit and Flexibility}

Milliman et al. (1991) proposed that two relationships between fit and flexibility have been set forth in the Strategic HRM literature. One view, the «orthogonal» perspective, argues that fit and flexibility are opposite ends of the same continuum. For example, Lengnick-Hall and Lengnick Hall stated that Research has shown that achieving fit is not always desirable.

Further, a focus on maximizing fit can be counterproductive if organization change is needed or if the firm has adopted conflicting competitive goals to correspond to a complex competitive Environment. (1988: 460).

Thus, while not specifically proposing a negative relationship Between fit and flexibility, these authors imply that the two cannot exist simultaneously.

The second view of the fit/flexibility relationship proposes that these variables are independent of one another, and Milliman et al. (1991) refer to this as the "complementary» perspective. This view argues that both concepts are essential for organizational effectiveness as the strategic management challenge is to cope with change (requiring flexibility) by continually adapting to achieve a fit between the firm and its external environment (Chakravarthy, 1982; Miles \& Snow, 1984).

Milliman et al. (1991) note that the differences between these two perspectives might stem from differences regarding the time frame and from differences regarding the goals of the research. In terms of the time frame, researchers advocating the orthogonal view are concerned with firms at one point in time, and argue both fit and flexibility cannot exist simultaneously, whereas advocates of the complementary view look at fit over a longer time horizon and explore adaptation processes. Regarding the goals of research, advocates of the orthogonal view are concerned with description (what firms actually do) whereas advocates of the complementary view seek to provide prescription (what firms ought to do).

Consistent with Milliman et al (1991), we propose that fit and flexibility are complementary, particularly because they focus on different aspects of organizations. Fit can be viewed as a state which exists at some level at a given point in time and because of its focus on an interface between two variables, has both internal (HR aspects) and external (strategy) components. Because fit deals with relationships among some set of dynamic contingent constructs, it can only be assessed as a snapshot; fit at time 1 in no way guarantees fit at time. This is why researchers interested in fit focus on a particular point in time (Milliman, et al., 1991).

Flexibility, on the other hand, is not a temporary state, but an actual characteristic (e.g., a trait) of an organization. Note that most definitions of flexibility refer to an «ability» to meet a variety of needs in a dynamic environment (e.g., Sanchez, 1995). In contrast to fit's focus on an interface of two variables, one internal and one external, flexibility is viewed as being purely internal in orientation. Flexibility is comprised of firm characteristics such as broad, heterogeneous skills/competencies of the workforce, organic administrative systems, etc. that enable a firm to adapt to some change in the environment (Chakravarthy, 1982). In essence, treatments of flexibility have focused on variety, malleability, or both.

Although flexibility is a characteristic that theoretically can be assessed at any point in time, it is more frequently assessed only over time. This is because while certain characteristics of the firm that comprise flexibility can be assessed at time 1, confirmatory evidence that flexibility existed at time 1 is best obtained by observing a successful adaptation to an environmental change at time 2 . Thus, flexibility is defined as the ability to achieve fit under a variety of environmental demands (Milliman et al., 1991). In contrast to the orthogonal view, this view proposes that fit and flexibility can exist at the same time.

Note that this treatment of fit and flexibility distinguishes the concepts as completely independent of one another. Fit does not equal inflexibility; similarly, misfit cannot be equated with flexibility. Flexibility is a characteristic of the firm which enables it to achieve a state of fit at any given point in time. Consequently, in our view, the primary role of Strategic HRM should be to promote a fit with the demands of the competitive environment. 
In a stable, predictable environment, this might be efficiently achieved by using bureaucratic systems which focus on developing a human capital pool with a narrow range of skills and HR systems which elicit a narrow range of employee behavior. In this case, once fit is achieved, flexibility becomes relatively unimportant.

However, today most firms face environments characterized by increasing dynamism and competition. In such a case, sustainable fit can only be achieved by developing a flexible Organization. Thus, Strategic HRM must increasingly promote organizational flexibility in order for the firm to achieve a dynamic fit.

\section{Research Hypothesis}

Based on the literature review the following hypotheses are tested in this research:

- H1: Availability of Flexibility HRM is positively related to employee engagement.

- $\quad$ H2: Use of Flexibility HRM is positively related to employee engagement.

- H3: Employee engagement partially mediates the relations between availability of flexibility HRM and job performance.

- H4: Employee engagement partially mediates the relations between use of flexibility HRM and job performance.

- H5: Employee age moderates the relations between (a) availability and (b) use of flexibility HRM and employee engagement, with stronger relations for younger workers.

\section{The Research Model}

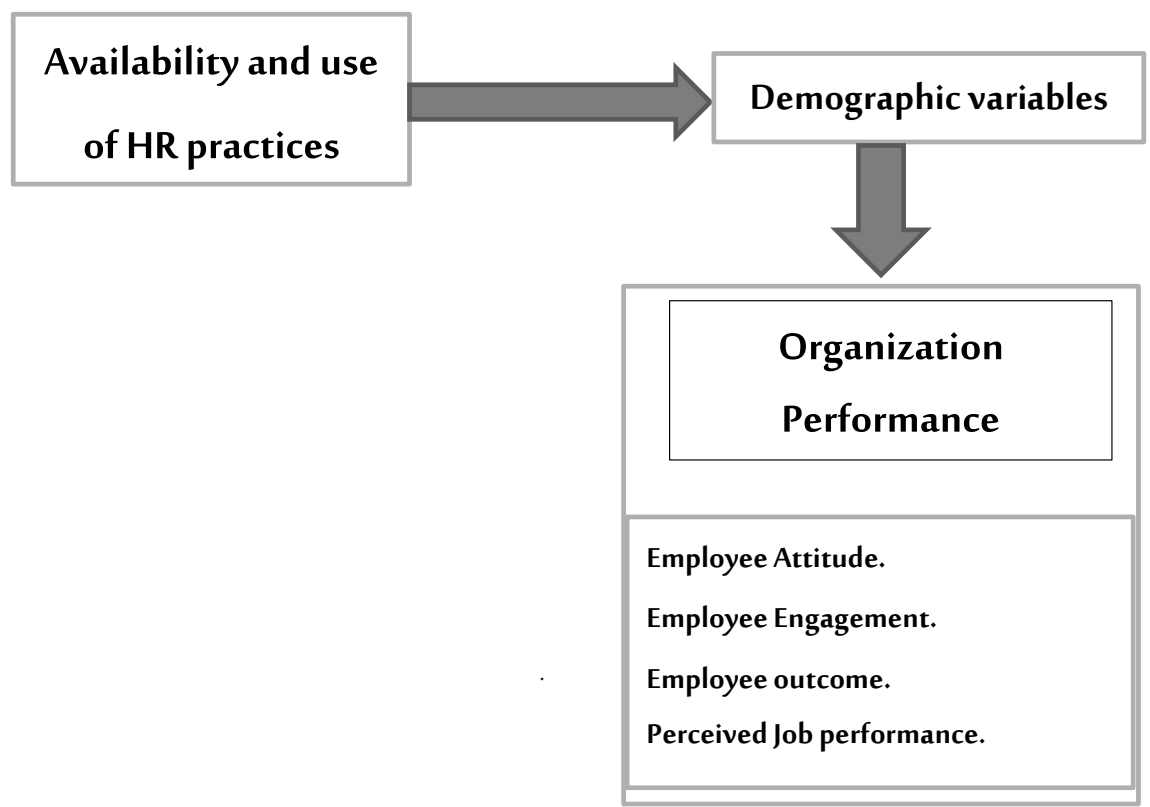

Figure 1 - The Research Model

\section{Measures}

Availability and use of flexibility HRM were measured at T1 using two 7-item scales: irregular flexibility practices and regular flexibility practices. In line with the majority of research on HRM, we measured the presence and use of HR practices as reflected in the perceptions of employees (Boselie, Dietz, \& Boon, 2005). Table 1 shows the items which were used to measure both scales (based on Hill et al., 2008). Availability was measured through asking employees whether they had access to a range of options. Responses were provided with no or yes. Irregular flexibility HRM targeted at HR practices that facilitate employees additional leave options from work (Bal et al., 2013; Kooij, Jansen, Dikkers, \& De Lange, 2014). 
Regular Flexibility targeted flexibility in the amount of regular hours and the schedule that employees worked. Use of flexibility HRM was measured using the same items as availability, and measured whether employees had taken advantage of these options (no or yes). Scores were calculated through the total number of yes-responses.

\section{Table 1: Summary of Measurement Items of Flexibility HR Practices}

\section{Study 1 Irregular Flexibility HRM (Availability/Use)}

- Sabbaticals or career breaks.

- Take paid or unpaid time for education or training to improve job skills

- Take a paid leave for care giving or other personal or family responsibilities

- Work part-year; that is work for a reduced amount of time on an annual basis

- Phase into retirement by working reduced hours over a period of time.

- Take extra unpaid vacation days.

- Take paid time off to volunteer in the community

\section{Regular Flexibility HRM (Availability/Use)}

- Choose a work schedule that varies from the typical schedule at your worksite

- Occasionally request changes in starting and quitting times.

- Frequently request changes in starting and quitting times, such as on a daily basis.

- Reduce your work hours and work on a part-time basis while remaining in the same position or at the same level.

- Structure jobs as a job share with another person where both receive their fair share of compensation and benefits.

- Compress the work week by working longer hours on fewer days for at least part of the year have input into the amount of overtime hours you work

\section{Study 2 Flexibility HRM (Availability/Use)}

- Flexibility in number of hours worked

- Flexible work schedules.

- Flexible space Options for time off.

- Flexibility in changing career path.

- Employee engagement $(\alpha=.93)$ was measured at T2 using the nine-item scale by Schaufeli and Bakker (2004). An example is «At work, I feel bursting with energy».

Answers were provided on a 7-point scale, ranging from 'never' to 'always/everyday'.

Perceived Job Performance was measured both at T1 $(\alpha=.85)$ and T2 $(\alpha=.86)$, using three items: «How would you rate your job performance, as an individual employee2», «Think about your most recent assessment of your job performance or the most recent time you received feedback from your supervisor.

How do you think your supervisor would rate your performance2», and «How would you rate your performance as a work team member2» Responses were provided on a 5-point Likert scale ( 1 = 'very poor', 5 = 'excellent'). Self-reported job performance was the selected outcome, since comparable objective performance ratings across the nine organizations were not available. Whereas self-rated job performance may be a less objective indicator of performance than measures such as sales rates (Williams \& Anderson, 1991), the measure of job performance that is used in the current study indicates an assessment by the employee about their performance on the job (see e.g., Bal, Jansen, Van der Velde, De Lange, \& Rousseau, 2010). Subjective 
performance measures are valid for the current study. First, objective and subjective measures of performance are positively correlated and are similarly predicted by independent variables (Bommer, Johnson, Rich, Podsakoff, \& MacKenzie, 1995; Wall et al., 2004). Moreover, subordinate's perceptions of their own performance add to other ratings of performance (e.g., objective performance and supervisor rated performance), since they contribute in a unique way to the overall concept of performance (Conway \& Huffcutt, 1997).

\section{Moderator and Control Variables.}

Age was measured as a continuous variable,indicating the age of the employee at the T1 measurement. We controlled for (measured at T1) gender ( $1=$ 'male', $2=$ 'female'), education ( 1 = 'less than high school', 7 = 'graduate degree'), organizational tenure (in years), the number of children 18 and younger, weekly working hours, and work status ( 1 = 'fulltime', 2 = 'part-time').

We controlled for these factors, since previous research has shown that they might be influencing the effectiveness of flexible work arrangements (Hill et al., 2008; Lee et al., 2000).

\section{Analysis}

To test the validity of the multi-item scales, we performed a confirmatory factor analysis (CFA) using Lisrel 8.80 (Jöreskog \& Sörbom, 2005), using the tetrachoric correlations of the binary variables (Uebersax, 2006). The proposed seven-factor model obtained a good fit $(\chi 2=122.24, \mathrm{df}=835, \mathrm{p}<.001 ; \mathrm{GFI}=.99$, SRMR $=.01$ ). All of the items loaded significantly on their respective factors. A model which included one factor for availability and one factor for use of flexibility HRM did not obtain significant better fit $(\Delta \chi 2=2.41, \Delta d f$ $=9$, ns), and a model with one factor for regular flexibility and one factor for irregular flexibility did also not obtain significant better fit $(\Delta \chi 2=8.70, \Delta d f=9, \mathrm{~ns})$.

The searcher also tested a model including the proposed factors and an unmeasured latent factor to control of common method bias (Podsakoff et al., 2012).

This model did not obtain a significant better fit than the proposed model $(\Delta \chi 2=96.75, \Delta d f=364$, $n s)$. Hence, there was no indication of common method bias in our data.

Because employees were nested in 8 different departments in 4 organizations, the searcher tested whether multilevel analyses should be conducted. First, the searcher compared a multilevel null-model, using only the intercept as predictor of the outcomes, with an ordinary regression analyses in order to ascertain whether there was statistical reason to conduct multilevel analyses, and subsequently calculated ICCscores (Hox, 2002). For work engagement, the searcher found a significant improvement of the multilevel over the ordinary regression analysis $(\Delta 2 x \log =39.38, \Delta d f=1, p<.001)$. However, only $6 \%$ of the variance in engagement was explained by differences among departments. For job performance, the searcher also obtained a significant difference $(\Delta 2 x \log =9.59, \Delta d f=1, p<.01)$, and an ICC of.03, indicating that only $3 \%$ of the variance in job performance was due to difference on Level 2. Given that the explained variance at Level 2 was marginal, and the number of Level-2 units were well below standards of 40 (Meuleman \& Biliet, 2009), it was deemed appropriate to use ordinary regression analyses.

Hypotheses were tested with bias-corrected bootstrapping using the PROCESS macro for SPSS (Hayes, 2013; Preacher, Rucker, \& Hayes, 2007). Independent variables were mean-centered to avoid multi-collinearity.

The searcher tested the relationships with eight dummy variables to control for the organizations employees worked for. Inclusion of these dummies did not affect the significance levels of our estimates, and for space reasons we report the results of the analyses without the dummy variables. Table 2 shows the correlations among the variables under study. Availability and use of both types of flexibility HRM were positively correlated with engagement ( $r$ 's ranging between.13 and.22). However, only irregular flexibility availability was related to job performance T1 and T2 (r=.08/.09, $p<.05)$, and regular flexibility use to job performance T1 and T2 $(r=.11 / .09, p<.05)$. 


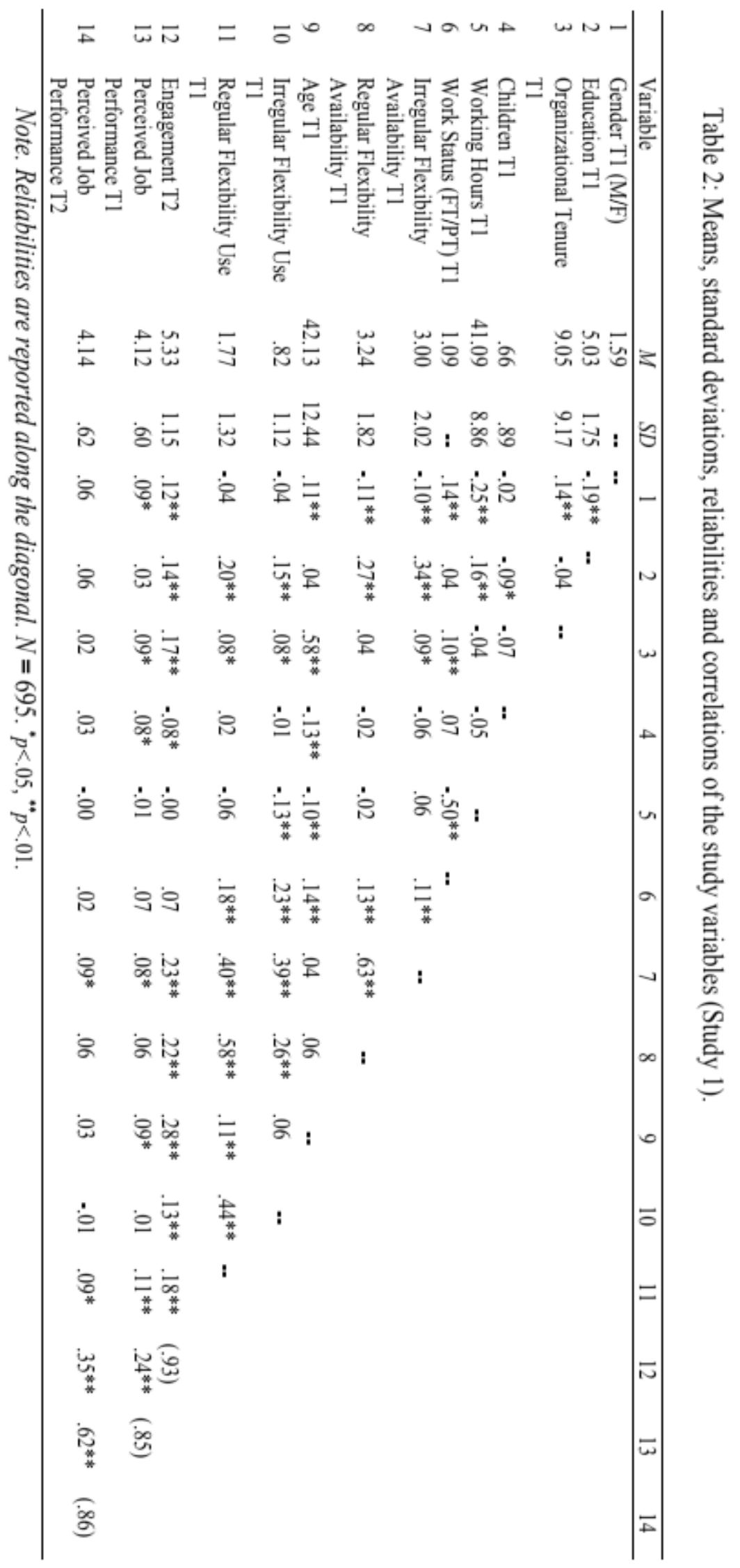




\section{Results}

Table 3 shows the results of the mediation analyses for flexibility HRM in relation to engagement and job performance, while Table 4 shows the results of the moderated analyses for flexibility HRM and age in relation to the outcomes. $16 \%$ of the variance in work engagement was explained by the predictors. $\mathrm{H} 1$ predicted that availability of flexibility HRM would be positively related to engagement. Availability of irregular flexibility was positively related to engagement $(b=.06, p<.05)$. Moreover, availability of regular flexibility was also positively related to engagement $(b=.07, \mathrm{p}<.05)$. $\mathrm{H} 1$ was fully supported. $\mathrm{H} 2$ predicted that use of flexibility HRM would be positively related to engagement. Use of irregular flexibility was not related to engagement $(b=.05, n s)$. Moreover, use of regular flexibility was also unrelated to Engagement $(b=.00, n s)$. Therefore, $\mathrm{H} 2$ was rejected; use of flexibility of HRM was not directly related to engagement.

Table 3: Mediated Regression Analyses of Flexibility HRM Predicting Engagement and Job Performance (Study 1).

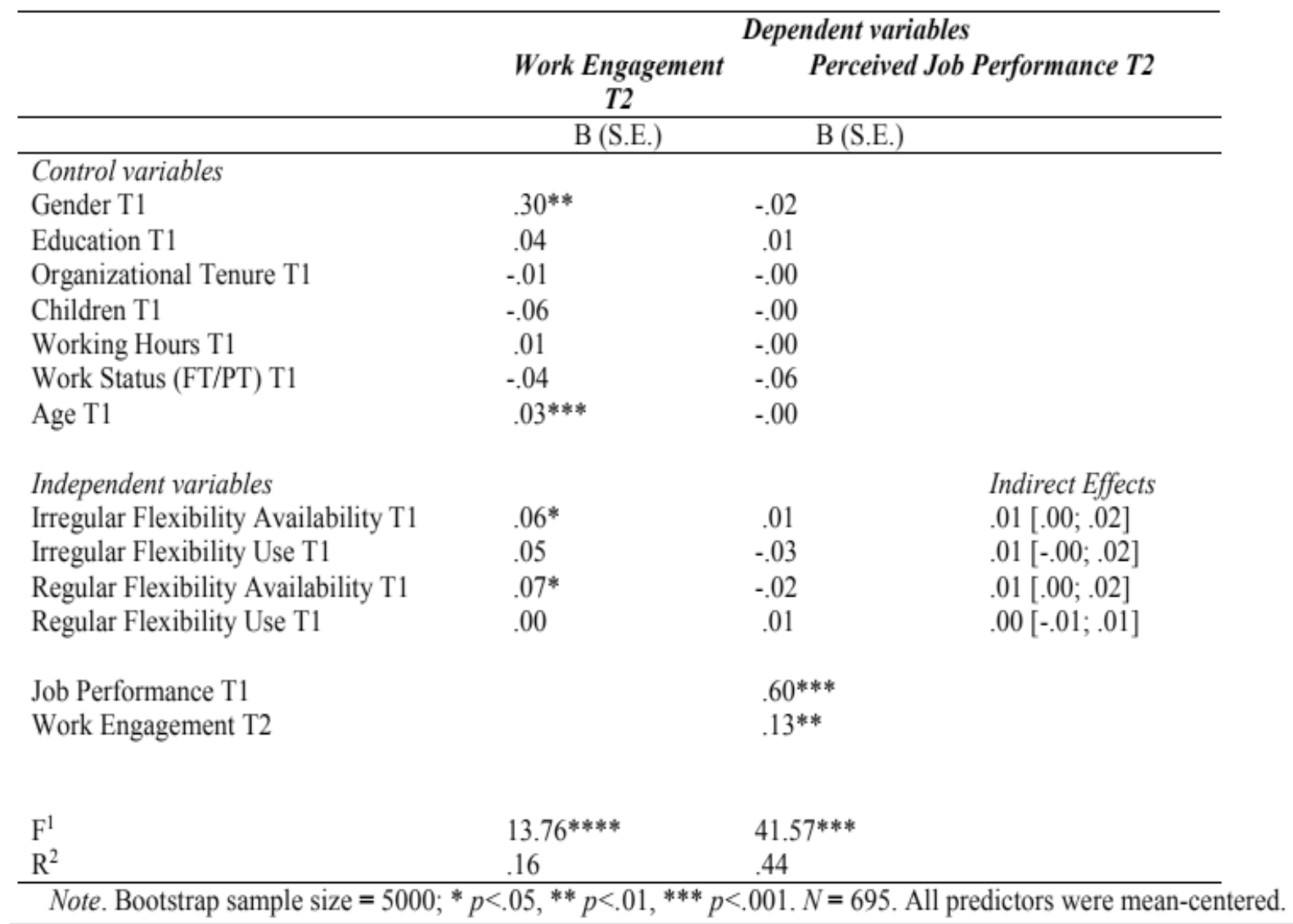




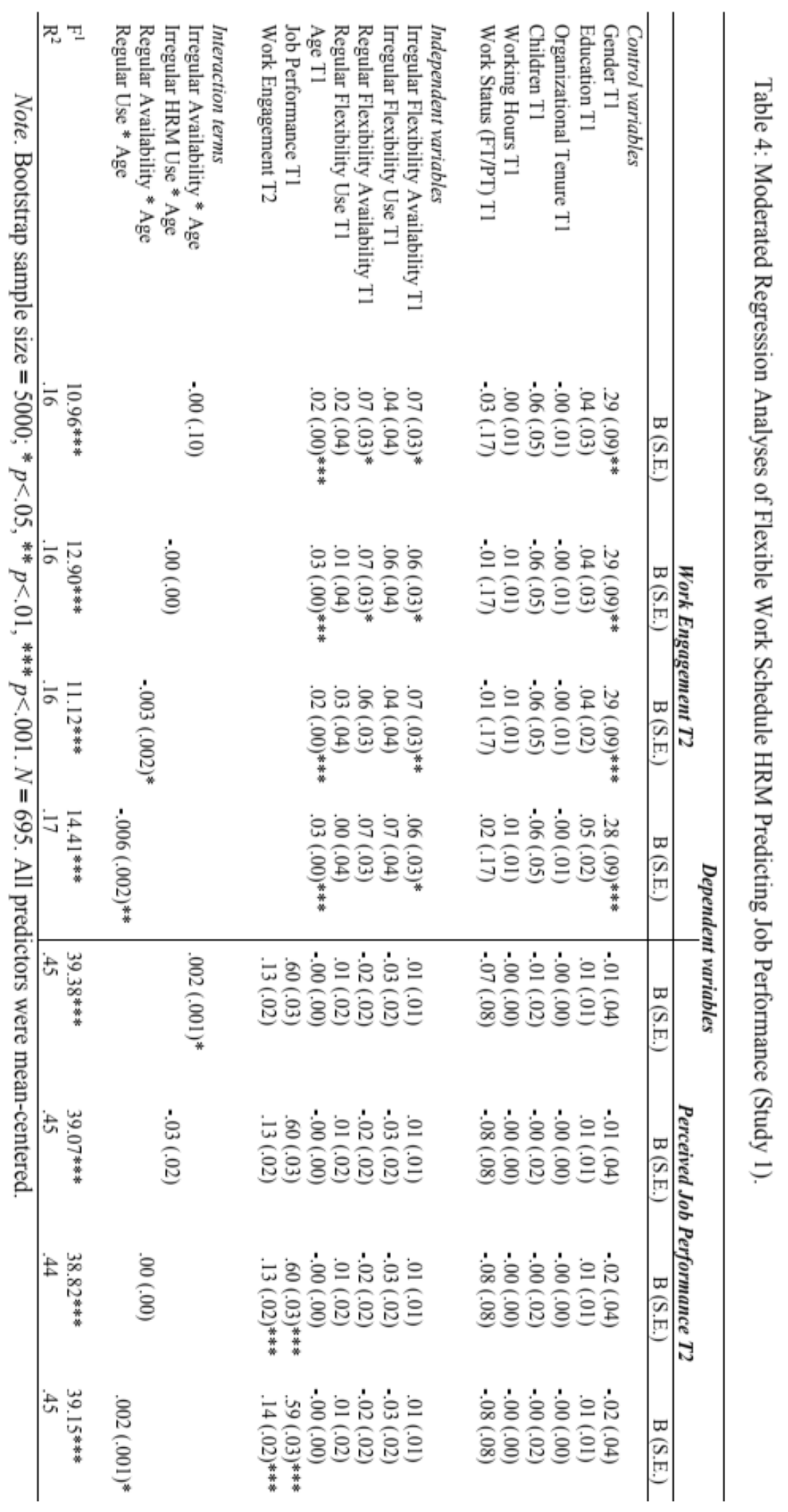


$\mathrm{H} 3$ and $\mathrm{H} 4$ predicted that engagement partially mediated the relations between availability and use of flexibility HRM with job performance. In the analyses, we controlled for the stability of job performance by including job performance T1 as a predictor $(\mathrm{b}=.60, p<.001)$. Table 3 shows that engagement was positively related to job performance $\mathrm{T} 2(\mathrm{~b}=.13, p<.001) .44 \%$ of the variance in job performance was explained by the predictors. Engagement positively mediated the relation between availability of irregular flexibility and job performance (Indirect effect $b=.01,95 \%$ Confidence Interval between.00 and.02). Because use of irregular flexibility was not significantly related to engagement, the indirect effect of use of irregular flexibility on job performance was also non-significant through engagement ( $b=.01, \mathrm{Cl}$ : -.00,.02). Engagement mediated the relation between availability of regular flexibility and job performance (indirect effect $b=.01$, $\mathrm{Cl}: .00, .02)$. Furthermore, engagement did not mediate the relation between use of regular flexibility and job performance ( $b=.00, \mathrm{Cl}:-.01, .01)$. In sum, $\mathrm{H} 3$ was supported, while $\mathrm{H} 4$ was rejected. Employee engagement mediated the relationships of availability of irregular and regular flexibility $\mathrm{HRM}$ with job performance over time. Use of irregular and regular flexibility was not directly or indirectly related to job performance over time. $\mathrm{H} 5$ and $\mathrm{H} 6$ predicted that age moderated the relations between flexibility HRM and engagement and job performance. Table 5 shows the results of the analyses. Significant interactions were reported with 3 decimals, to obtain clear estimates of the interaction effects. Age did not Further, age moderated the relation of availability $(b=-.003, p<.05, \Delta \mathrm{R} 2=1 \%)$ and use $(\mathrm{b}=-.007, p<.01, \Delta \mathrm{R} 2=1 \%)$ of regular flexibility with engagement. Figures 2 and 3 show the interaction patterns. Figure 2 shows that the relation of availability of regular flexibility was positive for younger workers $(b=.11, p<.01)$, while the relation was not significant for older workers $(b=.02, n s)$. We found similar relations for use of regular flexibility, which is shown in Figure 3. The slope for younger workers was positive $(b=.10, p<.05)$, while the slope was non-significant for older workers $(b=-.06, n s)$.

We also found a significant interaction of availability of irregular flexibility with age in relation to job performance $(\mathrm{b}=.002, p<.05, \Delta \mathrm{R} 2=1 \%)$. Figure 4 shows the interaction effect. The relation was not significant for younger workers ( 1 SD below the mean; $b=-.01, n s$ ), while the relation was positive for older workers ( 1 SD above the mean; $b=.03, p<.05$ ). We found no significant interaction of use of irregular HRM with age in relation to job performance $\mathrm{T} 2(\mathrm{~b}=-.03, n s)$.

Finally, age also moderated the relation between use regular flexibility and job performance T2 (b $=.002, p<.05, \Delta R 2=1 \%)$. Figure 5 shows the interaction pattern. The relation was not significant for younger workers $(b=-.02, n s)$, while it was positive for older workers $(b=.04, p<.05)$. In sum, we found partial support for $\mathrm{H} 5$, with stronger relations of availability and use of regular flexibility for younger workers in relation to engagement, and partial support for $\mathrm{H} 6$, with stronger relations among older workers for the relations of availability of irregular flexibility and use of regular flexibility in relation to job performance.

\section{Study 2 Methods}

\section{Participants and Procedure}

Study 2 was conducted from Jan 2018 until March 2018, in 4 different multinational companies in Egypt. These companies include consultancy, technical, pharmaceutical, financial service. Employees at 24 worksites in these organizations were emailed and asked to participate in the research. All employees were 
white-collar office workers. 2918 employees were invited to participate in the research by filling out an online survey. In total, 678 employees filled out the survey completely, resulting in a total response of $22.5 \%$. Distribution of respondents was: $26.7 \%$ from Juhaina co, $14.7 \%$ from Elmourdon Elmotahedon, 34.5\% from El dawlia for Carton, $23.1 \%$ from Nestle co, , the mean age was 37.5 years old, $38 \%$ was female, and $53 \%$ had no children. Mean organizational tenure with the organization was 8.79 years, and $99 \%$ worked fulltime. On average, employees worked 49 hours per week.

\section{Measures}

Availability and Use of Flexibility HRM was measured with six items measuring flexibility in work schedule and work space (Hill et al., 2008). Table 1 shows the items.

Availability was measured by asking employees whether their organization offered the six types of flexible work options to them (no, yes). Use was measured through asking participants whether they had used the options over the past year (no or yes). Scale scores were calculated through the total number of yes-responses.

Employee Engagement $(\alpha=.88)$ was measured with an adapted engagement scale of Schaufeli and Bakker (2004), using four items: «At my work, I feel bursting with energy», «I find the work that I do full of meaning and purpose», «l am enthusiastic about my job», and «l am immersed in my work». Due to restriction on survey length, we used a four-item scale, while retaining items from the three sub dimensions vigor, dedication, and absorption. Responses could be provided on a 7-point scale ( 1 = 'never', 7 = always, every day you work').

Perceived Job Performance $(\alpha=.81)$ was measured with two items measuring the overall job performance of the employee.

The items were: «How do you think your supervisor would rate your job performance2», and «How would you rate your own job performance2» Responses were provided on a 6-point Likert scale (1 = 'very poor', 6 = 'excellent').

\section{Moderator and Control Variables}

Age was measured as a continuous variable. Collectivism scores were obtained for the organizations from the GLOBE study (House et al., 2004).

The Globe-project distinguishes between cultural dimensions based on 'what should be' versus 'what is'. The searcher focuses on the latter scores, which measure common behaviors, institutional practices, and prescriptions in various cultures.

The searcher controlled for the influence of gender ( 1 = 'male', 1 = 'female'), highest obtained education ( 1 = 'less than college', 3 = 'graduate degree'), organizational tenure (in years), dependent children living at home $(0=$ 'no', $1=$ 'yes'), the amount of hours employees worked per week, and work status $(0=$ 'fulltime', 1 = 'part-time'). 


\section{Analysis}

The searcher first performed a CFA to test the factor structure, using the tetrachoric correlations of the binary variables (Uebersax, 2006). The proposed 4-factor model (flexibility availability and use, engagement, performance) obtained acceptable fit $(\chi 2=1300.54, d f=82, p<.001$; GFI =.93, SRMR =.07). Moreover, all of the items loaded significantly on their respective factors.

The proposed model obtained a significant better fit than a one-factor model $(\Delta \chi 2=10443.51, \Delta d f=$ $6, p<.001)$, and a model with a common method factor $(\Delta \chi 2=1451.20, \Delta d f=1, p<.001)$. Hence, there was no indication of common method bias in the data (Podsakoff et al., 2012).

Subsequently, the searcher tested whether it was appropriate to conduct multilevel analyses, since respondents were nested in 24 worksites and in 11 countries. For both engagement and performance, multilevel regression analyses using worksites as Level 2 obtained better fit than ordinary regression analyses (engagement: $\Delta 2 x \log =55.715, p<.001$; job performance: $\Delta 2 x \log =189.926, p<.001$ ). $14 \%$ of the variance in engagement, and $32 \%$ of the variance in performance were explained at level 2 . Adding a third country-level did not produce a significant better fit for both engagement and performance, so it was deemed appropriate to proceed with multi-level analyses, using work sites as Level 2 indicators.

To test the hypotheses, the searcher applied multilevel analyses using MLWin 2.24 (Rasbash et al., 2000). Independent variables were standardized before interactions were calculated. Moreover, to take into account the different cultural contexts, The searcher added collectivism as a Level 2 moderator, and assessed whether the relations between flexibility HRM, age and the outcomes, were additionally moderated by collectivism. Table 5 shows the correlations among the variables, and table 6 shows the results of the multilevel analyses. Table 5 shows that flexibility availability is positively correlated with engagement $(r$ $=.06, \mathrm{p}<.05)$, while flexibility use was positively Correlated with job performance $(r=.14, \mathrm{p}<.01)$. Moreover engagement was positively related to job performance $(r=.36, p<.01)$.

Table 5: Means, standard deviations, reliabilities and correlations of the study variables (Study 2).

\begin{tabular}{|c|c|c|c|c|c|c|c|c|c|c|c|c|c|c|c|}
\hline & Variable & $M$ & $S D$ & 1 & 2 & 3 & 4 & 5 & 6 & 7 & 8 & 9 & 10 & 11 & 12 \\
\hline 1 & Gender $(\mathrm{M} / \mathrm{F})$ & 1.38 & - & 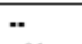 & & & & & & & & & & & \\
\hline 2 & Education & 2.11 & .66 & .01 & .. & & & & & & & & & & \\
\hline 3 & Organizational Tenure & 8.79 & 8.01 & $-.10^{* *}$ & $-.12^{* *}$ & .. & & & & & & & & & \\
\hline 4 & No. of Children & .44 & .48 &. $.13^{* *}$ & $\cdot .00$ & $.15^{*}$ & .. & & & & & & & & \\
\hline 5 & Working Hours & 49.00 & 11.52 &. $.12^{* *}$ & .01 & .03 & $.09^{* *}$ & .. & & & & & & & \\
\hline 6 & Work Status (FT/PT) & .01 & .. & .04 & .01 & -.01 & .00 & $-.11^{* *}$ & .- & & & & & & \\
\hline 7 & $\begin{array}{l}\text { Flexibility HRM } \\
\text { Availability }\end{array}$ & 2.89 & 1.64 & .03 & $.08^{* *}$ & $.07^{* *}$ & .03 & .02 & -.01 & .. & & & & & \\
\hline 8 & Age & 37.55 & 9.41 & $-.09^{* *}$ & .00 & $.67^{* *}$ & $.23^{* *}$ & .02 & .03 & $.15^{* *}$ & .. & & & & \\
\hline 9 & Collectivism (Level 2) & 4.48 & .51 & $-.15^{* *}$ & $.13^{* *}$ & $.14^{* *}$ & .00 & $.16^{* *}$ & $-.07^{* *}$ & $.11^{* *}$ & .04 & .. & & & \\
\hline 10 & Flexibility HRM Use & 1.81 & 1.09 & .01 & -.01 & $-10^{* *}$ & .02 & .02 & .03 & .04 & $-10^{* *}$ & $-.09^{* *}$ & .. & & \\
\hline 11 & Engagement & 5.51 & 1.19 & $-.07^{* *}$ & .02 & .03 & $.12^{* *}$ & $.12^{* *}$ & $-.05^{*}$ & $.06^{*}$ & $.11^{* *}$ & $-13^{* *}$ & .03 & $(.88)$ & \\
\hline 12 & $\begin{array}{l}\text { Perceived Job } \\
\text { Performance }\end{array}$ & 4.54 & .87 & $.10^{* *}$ & .03 & $-.06^{* *}$ & $.07^{* *}$ & .02 & .03 & .04 & $.05^{*}$ & $-.48^{* *}$ & $.14^{* *}$ & $.36^{* *}$ & (.81) \\
\hline
\end{tabular}

Note. Reliabilities are reported along the diagonal. $N=2,158 .{ }^{*} p<.05, " p<.01$. 


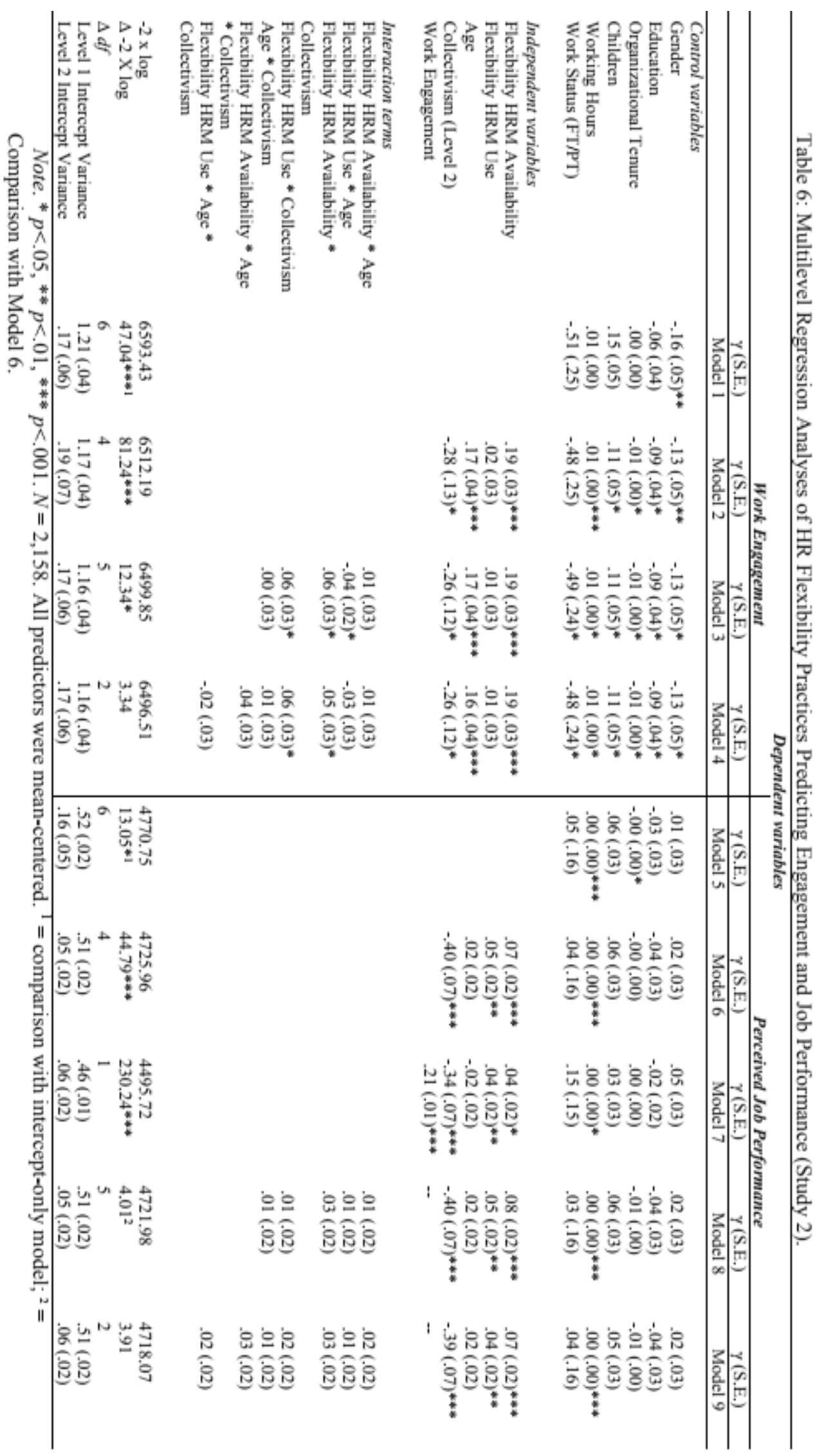




\section{Results}

$\mathrm{H} 1$ and $\mathrm{H} 2$ predicted that availability and use of flexibility HRM would be positively related to engagement. Table 6 shows the results. Availability of flexibility HRM was positively related to engagement $(\mathrm{b}=.19, p<.001$, Model 2). Hence, $\mathrm{H} 1$ was supported. Use of flexibility HRM was unrelated to engagement $(\mathrm{b}=.02, n s)$ and thus, $\mathrm{H} 2$ was rejected. $\mathrm{H} 3$ and $\mathrm{H} 4$ predicted that engagement mediated the relations between flexibility HRM and job performance. Availability ( $b=.07, p<.001$, Model 6$)$, and use $(b=.05, p<.01)$ of flexibility HRM were positively related to job performance. Engagement was also positively related to job performance ( $b=.21, p<.001$, Model 7 ). After adding engagement, the relations of availability and use of flexibility HRM were still significant but became smaller. The mediating effect of engagement was significant for availability $(z=6.06, p<.001)$, but not for use of flexibility HRM $(z=.67, n s)$. Hence, H3 was supported, while $\mathrm{H} 4$ was rejected.

$\mathrm{H} 5$ and $\mathrm{H} 6$ predicted that age moderated the relations between flexibility HRM and engagement and job performance. Age did not moderate the relation between availability of flexibility HRM and engagement ( $b=.01, n s$; Model 3$)$, but it did moderate the relation between use of flexibility HRM and engagement $(b=-.04, p<.05)$. Figure 6 shows the interaction pattern. The relation was positive for younger workers $(b$ $=.05, p<.05)$, while the relation was not significant for older workers $(b=-.03, n s)$. Hence, H5a was rejected and $\mathrm{H} 5 \mathrm{~b}$ was supported. Age did not moderate the relations between availability ( $b=.01, n s$; Model 8$)$ or use $(b=.01, n s)$ of Flexibility HRM and job performance.

Hence, $\mathrm{H} 6$ was rejected; the relations of availability and use flexibility HRM with job performance were no stronger for older workers.

In addition, the searcher also ascertained whether the relations of flexibility HRM and age with engagement and performance were differing as a function of national culture. The searcher tested whether the relationships of flexibility HRM with the outcomes were influenced by culture, but also whether the interaction effects of flexibility HRM with age were moderated by culture. Adding collectivism as a unit-level moderator showed that in more collectivistic Organizations engagement $(b=-.28, p<.05)$ and performance $(b=-.40, p<.001)$ was lower. Moreover the relation of use of flexibility HRM with engagement was moderated by collectivism $(b=.06, p<.05)$. However, the relations for both low collectivistic Organizations ( $1 \mathrm{SD}$ below the mean) and high collectivistic Organizations (1 SD above the mean) were non-significant. Only at extreme high levels of collectivism, the relation became significant. Thus, we did not find evidence for cultural differences among the countries in the relationships under study.

As in Study 1, we also tested the moderating role of gender, number of children, and curvilinear effects of age on the relations between flexibility HRM and the outcomes.

Again, none of the interactions were significant, thus providing evidence for the moderating role of age rather than gender, dependent children at home, or nonlinear effects of age.

\section{Conclusion}

This study investigated the effects of availability and use of flexibility HRM on employee engagement and performance. 
It was predicted and found that availability of flexibility HRM would be positively related to employee engagement and performance. Hence, this research provides some further evidence for the business case for flexibility HRM (De Menezes \& Kelliher, 2011).

Furthermore, it was found that younger workers reported higher engagement when they used flexibility HRM. Furthermore, older workers' perceived job performance increased when they used flexibility HRM. In sum, this study shows that to ascertain the effects of flexibility HRM, it is crucial to take employee age into account.

Finally, research on aging workers has traditionally focused on the differences between younger and older worker in their motives, attitudes and reactions to job characteristics (e.g., Kooij et al., 2008; Zaniboni, Truxillo, \& Fraccaroli, 2013). However, these studies have largely taken a perspective of older workers as passive recipients of job characteristics. The current study shows that when older workers receive more flexibility in how they balance work obligations with non-work obligations, their performance may increase. This perspective fits within the recent trend of individualization of work arrangements, such that older workers can take an individual approach to maintain motivation and productivity (Bal et al., 2012). Hence, flexibility may be very crucial in maintaining employees' capabilities to extend their working lives, and for instance to continue working beyond retirement (Bal et al., 2012).

Managers who introduce or enhance the use of flexible HRM face several issues. They might work on a reciprocal basis with (voluntary) freelancers and thereby increase organizational performance and become more innovative.

On the other hand, they might have introduced flexible HRM practices in order to enhance organizational flexibility - and still wait for the 'reality test' of their implemented practices. On the other hand, however, practitioners can be accused of provoking socially detrimental effects or merely exploiting contingent workers. Furthermore, they may introduce flexible HRM in order to increase performance, but these expectations may remain unfulfilled. Therefore, practitioners face similar problems in dealing with flexible HRM. 


\section{References}

- Armstrong-Stassen, M. and Ursel, N. D. (2009). «Perceived organizational support, career satisfaction, and the retention of older workers», Journal of Occupational and Organizational Psychology, 82, 201-220.

- Baltes, B. B.; Briggs, T. E.; Huff, J. W.; Wright, J. A. and Neuman, G. A. (1999). «Flexible and compressed workweek schedules: a meta-analysis of their effects on work-related criteria», Journal of Applied Psychology, 84, 496-513.

- Baltes, P. B. (1997). «On the incomplete architecture of human ontogeny: Selection optimization and compensation as foundation», American Psychologist, 52, 366-380.

- Baltes, P. B. and Baltes, M. M. (1990). «Psychological perspectives on successful aging: The model of selective optimization with compensation». In: Baltes, P. B. and Baltes, M. M. (Eds.) Successful Aging: Perspectives From the Behavioural Sciences. New York: Cambridge University Press, 1-34.

- Barney, J. (1991). «Firm Resources and Sustained Competitive Advantage», Journal of Management, 17, 99-120.

- Beck, U. (2000). The brave new world of work. Cambridge, UK: Polity Press.

- Bickerton, G. R.; Miner, M. H.; Dowson, M. and Griffin, B. (2014). «Spiritual resources and work engagement among religious workers: A three-wave longitudinal study», Journal of Occupational and Organizational Psychology, 87, 370-391.

- Bommer, W.H.; Johnson, J. L.; Rich, G. A.; Podsakoff, P. M. and MacKenzie, S. B. (1995). «On the interchangeability of objective and subjective measures of employee performance: a meta-analysis», Personnel Psychology, 48, 587-605.

- Boselie, P.; Dietz, G. and Boon, C. (2005). «Commonalities and contradictions in HRM and performance research», Human Resource Management Journal, 15, 67-94.

- Boxall, P. and Purcell, J. (2011). Strategy and human resource management. $3^{\text {rd }}$ ed. New York: Palgrave Macmillan.

- Casper, W. J. and Harris, C. M. (2008). «Work-life benefits and organizational attachment: self-interest utility and signalling theory models», Journal of Vocational Behavior, 72, 95-109.

- Christian, M. S.; Garza, A. S. and Slaughter, J. E. (2011). «Work engagement: A quantitative review and test of its relations with task and contextual performance», Personnel Psychology, 64, 89136.

- Conway, J. M. and Huffcutt, A. I. (1997). «Psychometric properties of multisource performance ratings: a meta-analysis of subordinate, supervisor, peer, and self-ratings», Human Performance, 10, 331-360.

- Cooper, M. (2008). «The inequality of security: Winners and losers in the risk society», Human Relations, 61 (9), 1229-1258.

- Crawford, E. R.; LePine, J. A. and Rich, B. L. (2010). «Linking job demands and resources to employee engagement and burnout: a theoretical extension and meta-analytic test», Journal of Applied Psychology, 95, 834-848.

- Davidson, O. B.; Eden, D.; Westman, M. Cohen-Charash, Y.; Hammer, L. B.; Kluger, A. N., et al. (2010). «Sabbatical leave: Who gains and how much», Journal of Applied Psychology, 95, 953964.

- De Hauw, S. and De Vos, A. (2010). «Millennials' career perspective and psychological contract expectations: does the recession lead to lowered expectations», Journal of Business and Psychol- 
ogy, 25, 293-302.

- De Lange, A. H; Kooij, T. A. M.; Van der Heijden, B. I. J. M. (2014). «Human resource management and sustainability at work across the life-span: an integral perspective», In: D. Truxillio, L. Finkelstein, R. Kanfer (eds.) Frontiers in Psychology.

- De Menezes, L. M. and Kelliher, C. (2011). «Flexible working and performance: a systematic review of the evidence for a business case», International Journal of Management Reviews, 13, 452-474.

- De Menezes, L. M. and Kelliher, C. (2011). «Flexible working and performance: a systematic review of the evidence for a business case», InternationalJournal of Management Reviews, 13, 452-474.

- Docherty, P.; Forslin, J.; Shani, A. B. and Kira, M. (2002). «Emerging work systems: from intensive to sustainable», In P. Docherty; J. Forselin and A. B. Shani (eds.), Creating Sustainable Work Systems: Emerging Perspectives and Practice, (pp. 3-14). London: Routledge.

- Doogan, K. (2001). «Insecurity and long-term employment», Work, Employment \& Society, 15 (3), 419-441.

- $\quad$ Ford, M. T.; Matthews, R. A.; Wooldridge, J. D.; Mishra, V.; Kakar, U. M. and Strahan, S. R. (2014). «How do occupational stressor-strain effects vary with time $2 \mathrm{~A}$ review and meta-analysis of the relevance of time lags in longitudinal studies», Work \& Stress, 28, 9-30.

- Gerwin, D. (1993). «Manufacturing flexibility: A strategic perspective», Management Science, 39 (4), 395-410.

- Halbesleben, J. R.; Neveu, J. P.; Paustian-Underdahl, S. C. and Westman, M. (2014). «Getting to the «COR»: understanding the role of resources in conservation of resources theory», Journal of Management, 40, 1334-1364.

- Hamel, G. and Prahalad, C. K. (1994). Competing for the Future. Cambridge, MA: Harvard Business School Press.

- Hayes, A. F. (2013). Introduction to Mediation, Moderation, and Conditional Process Analysis: $A$ regression-based approach. New York: Guildford Press.

- Herrbach, O., Mignonac, K., Vandenberghe, C., \& Negrini, A. (2009). «Perceived HRM practices, organizational commitment, and voluntary early retirement among late-career managers», Human Resource Management, 48, 895-915.

- Herrbach, O.; Mignonac, K.; Vandenberghe, C. and Negrini, A. (2009). «Perceived HRM practices, organizational commitment, and voluntary early retirement among late-career managers», $\mathbf{H u -}$ man Resource Management, 48, 895-915.

- Hess, N. and Jepsen, D. M. (2009). «Career stage and generational differences in psychological contracts», Career Development International, 14, 261-283.

- Hesseling, D. J. K. and Van Vuuren, T. (1999). «ob flexibility and job insecurity: The Dutch case.», European Journal of Work and Organizational Psychology, 8 (2), 273-293.

- Hill, E. J .; Grzywacz, J. G.; Allen, S.; Blanchard, V. L.; Matz-Costa, C.; Shulkin, S. et al. (2008). «Defining and conceptualizing workplace flexibility», Community, Work \& Family, 11, 149-163.

- Hobfoll, S. (1989). «Conservation of resources», American Psychologist, 44, 513-524.

- House, R. J.; Hanges, P. J.; Javidan, M.; Dorfman, P. W. and Gupta, V. (2004). Culture, Leadership, and Organizations. Thousand Oaks, CA: Sage.

- Hox, J. J. (2002). Multilevel analysis: Techniques and applications. Mahwah, NJ: Lawrence Erlbaum.

- Huselid, M. A. (1995). «The impact of human resource management practices on turnover, Pro- 
ductivity and corporate financial performance», Academy of Management Journal, 38: 635-672.

- Jöreskog, K. and Sörbom, D. (2005). Lisrel 8.72. Chicago: Scientific Software International.

- Kalleberg, A. L. (2000). «Nonstandard employment relations: Part-time, temporary and contract work», Annual Review of Sociology, 26, 341-365.

- Kanfer, R. and Ackerman, P. L. (2004). «Aging, adult development and work motivation», Academy of Management Review, 29, 440-458.

- Kerr, J. L. and Jackofsky, E. F. (1989). «Aligning managers with strategies: Management development versus selection», Strategic Management Journal, 10: 157-170.

- Kooij, D.; De Lange, A.; Jansen, P. and Dikkers, J. (2008). «Older workers' motivation to continue to work: five meanings of age», Journal of Managerial Psychology, 23, 364-394.

- Kooij, D. T. A. M.; Guest, D. E.; Clinton, M. Knight, T.; Jansen, P. G. W., et al. (2013). «How the impact of HR practices on employee well-being and performance changes with age», Human Resource Management Journal, 23, 18-35.

- Kooij, D. T. A. M.; Jansen, P. G. W.; Dikkers, J. S. E. and De Lange, A. H. (2014). «Managing aging workers: a mixed methods study on bundles of HR practices for aging workers», International Journal of Human Resource Management, 25, 2192-2212.

- Lado, A. A. and Wilson, M. C. (1994). «Human resource systems and sustained competitive Advantage: A competency-based perspective», Academy of Management Review, 19 (4): 699-727.

- Lai, P. C.; Soltani, E. and Baum, T. (2008). «Distancing flexibility in the hotel industry: the role of employment agencies as labor suppliers», The International Journal of Human Resource Management, 19 (1), 132- 152.

- Lambert, S. J. (2008). «Passing the buck: Labor flexibility practices that transfer risk onto hourly workers», Human Relations, 61 (9), 1203-1227.

- Lee, M. D.; MacDermid, S. M. and Buck, M. L. (2000). «Organizational paradigms of reduced-load work: accommodation, elaboration, and transformation», Academy of Management Journal, 43, 1211-1226.

- Leslie, L. M.; Manchester, C.F.; Park, T. Y. and Mehng, S. A. (2012). «Flexible work practices: a source of career premiums or penalties», Academy of Management Journal, 55, 1407-1428.

- Lewis, S.; Rapoport, R. and Gambles, R. (2003). «Reflections on the integration of paid work and the rest of life», Journal of Managerial Psychology, 18, 824-841.

- Lewis, S.; Rapoport, R. and Gambles, R. (2003). «Reflections on the integration of paid work and the rest of life», Journal of Managerial Psychology, 18, 824-841.

- Lub, X.; Bijvank, M. N.; Bal, P. M.; Blomme, R. and Schalk, R. (2012). «Different or alike2 Exploring the psychological contract and commitment of different generations of hospitality workers», International Journal of Contemporary Hospitality Management, 24, 553-573.

- Lyons, S. and Kuron, L. (2014). «Generational differences in the workplace: A review of the evidence and directions for future research», Journal of Organizational Behavior, 35, S139-S157.

- Lyons, S. and Kuron, L. (2014). «Generational differences in the workplace: A review of the evidence and directions for future research», Journal of Organizational Behavior, 35, S139-S157.

- Masuda, A. D., Poelmans, S. A. Y., Allen, T. D., Spector, P. E., Lapierre, L. M., Cooper, C. L. et al. (2012). «Flexible work arrangements availability and their relationship with work-to-family conflict, job satisfaction, and turnover intentions: a comparison of three country clusters», Applied Psychology: An International Review, 61, 1-29. 
- Masuda, A. D.; Poelmans, S. A. Y.; Allen, T. D.; Spector, P. E.; Lapierre, L.M.; Cooper, C.L. et al. (2012). «Flexible work arrangements availability and their relationship with work-to-family conflict, job satisfaction, and turnover intentions: a comparison of three country clusters», Applied Psychology: An International Review, 61, 1-29.

- Mayne, L.; Tregaskis, O. and Brewster, C. (1996). «A comparative analysis of the link between flexibility and HRM strategy", Employee Relations, 18(3), 5-24.

- Meuleman, B. and Billiet, J. (2009). «A Monte Carlo sample size study: How many countries are needed for accurate multilevel SEM», Survey Research Methods, 3, 45-58.

- Ng, E. S. W.; Schweitzer, L. and Lyons, S. T. (2010). «New generation, great expectations: a field study of the Millennial generation», Journal of Business Psychology, 25, 281-292.

- Parry, E. and Urwin, P. (2011). «Generational differences in work values: a review of theory and evidence», International Journal of Management Reviews, 13, 79-96.

- Peretz, H. and Fried, Y. (2012). «National cultures, performance appraisal practices, and organizational absenteeism and turnover: A study across 21 countries», Journal of Applied Psychology, 97, 448-459.

- Peretz, H. and Fried, Y. (2012). «National cultures, performance appraisal practices, and organizational absenteeism and turnover: a study across 21 countries», Journal of Applied Psychology, 97, 448-459.

- Pitt-Catsouphes, M. and Matz-Costa, C. (2008). «The multi-generational workforce: workplace flexibility and engagement», Community, Work \& Family, 11, 215-229.

- Podsakoff, P. M.; MacKenzie, S. B. and Podsakoff, N. P. (2012). «Sources of method bias in social science research and recommendations on how to control it», Annual Review of Psychology, 63, 539-569.

- Preacher, K. J.; Rucker, D. D. and Hayes, A. F. (2007). «Addressing moderated mediation hypotheses: Theory, methods, and prescriptions», Multivariate Behavioral Research, 42, 185-227.

- Rasbash, J.; Browne, W.; Haealy, M.; Cameron, B. and Charlton, C. (2000). M/win Version 2. 1: Interactive Software for Multilevel Analysis. London: Multilevel Models Project Institute of Education University of London.

- Rousseau, D. M. (2005). I-Deals: Idiosyncratic Deals Employees Bargain for Themselves. New York: M. E. Sharpe.

- Rynes, S. L.; Bretz, R. D. and Gerhart, B. (1991). «The importance of recruitment in job choice: A different way of looking», Personnel Psychology, 44, 487-521.

- Sanchez, R. (1995). «Strategic flexibility in product competition», Strategic Management Journal, 16, 135-159.

- Schaufeli, W. B. and Bakker, A. B. (2004). «Job demands, job resources, and their relationship with burnout and engagement: a multi-sample study», Journal of Organizational Behavior, 25, 293315.

- Schuler, R.S. and MacMillan, I. C. (1984). «Gaining competitive advantage through human resource Management practices», Human Resource Management, 23 (3): 241-255.

- Smola, K. W. and Sutton, C. D. (2002). «Generational differences: revisiting generational work values for the new millennium», Journal of Organizational Behavior, 23, 363-382.

- Snell, S. A.; Youndt, M. A. and Wright, P. M. (1996). «Establishing a framework for research in strategic human resource management: Merging resource theory and organizational learning», In: G.R. 
Ferris (Ed.) Research in Personnel and Human Resources Management, Vol. 14.

- Snow, C. C. and Snell, S. A. (1992). Staffing as strategy. In N. Schmitt, W. Borman \& Associates (Eds.) Personnel Selection in Organizations. San Francisco, CA: Jossey-Bass.

- Spence, M. (1973). «Job market signaling», The Quarterly Journal of Economics, 87, 355-374.

- Strazdins, L.; D'Souza, R. M.; Lim, L.; Broom, D. H. and Rodgers, B. (2004). «job strain, job security, and health: Rethinking the relationship», Journal of Occupational Health Psychology, 9, 443-475.

- Takeuchi, R.; Chen, G. and Lepak, D. P. (2009). «Through the looking glass of a social system: cross-level effects of high-performance work systems on employees' attitudes», Personnel Psychology, 62, 1-29.

- $\quad$ Twenge, J. M.; Campbell, S. M.; Hoffman, B. J. and Lance, C. E. (2010). «Generational differences in work values: leisure and extrinsic values increasing, social and intrinsic values decreasing», Journal of Management, 36, 1117-1142.

- Twenge, J. M.; Campbell, S. M. and Freeman, E.C. (2012). «Generational differences in young adults' life goals, concern for others, and civic orientation, 1966-2009», Journal of Personality and Social Psychology, 102,1045-1062.

- Uebersax, J. S. (2006). The tetrachoric and polychoric correlation coefficients. Statistical methods for rater agreement web site. http://www.john-uebersax.com/stat/tetra.htm\#soft (accesses on 23 August, 2013).

- United Nations (2009). Population Ageing and Development 2009. New York: United Nations, Department of Economic and Social Affairs.

- Wall, T. D.; Michie, J.; Patterson, M., et al. (2004). «On the validity of subjective measures of company performance», Personnel Psychology, 57, 95-118.

- Williams, L. J. and Anderson, S. E. (1991). «ob satisfaction and organizational commitment as predictors of organizational citizenship and in-role behaviors», Journal of Management, 17, 601617.

- Wilthagen, T. and Tros, F. (2004). «The concept of 'flexicurity': A new approach to regulating employment and labor markets. Transfer», European Review of Labour and Research, 10 (2), 166-186.

- Wright, P. and Snell, S. A. (1998). «Toward a unifying framework for exploring fit and flexibility in strategic human resource management», Academy of Management Review, 23(4), 756-772.

- Wright, P. M.; McMahan, G. C. and McWilliams, A. (1994). «Human resources and sustained Competitive advantage: A resource-based perspective», International Journal of Human Resource Management, 5 (2): 301-326.

- Wright, P. M. and Haggerty, J. J. (2005). «Missing variables in theories of strategic human resource management: time, cause, and individuals», Management Revue, 16, 164-173.

- Zacher, H.; Jimmieson, N. L. and Winter, G. (2012). «Eldercare demands, mental health, and work performance: the moderating role of satisfaction with eldercare tasks», Journal of Occupational Health Psychology, 17, 52-64.

- Zaniboni, S.; Truxillo, D. M. and Fraccaroli, F. (2013). «Differential effects of task variety and skill variety on burnout and turnover intentions for older and younger workers», European Journal of Work and Organizational Psychology, 22, 306-317. 